\title{
Menstrual Hygiene Practices among Junior Secondary School Students in Benin City
}

\author{
Lucy Ameze Gharoro \\ Department of Vocational and Technical Education, \\ University of Benin, Benin City, Nigeria
}

\section{Doi:10.5901/jesr.2013.v3n8p129}

\begin{abstract}
The study assessed the menstrual hygiene practices and challenges of junior school students during menstrual periods, with its implication for Home economics education. The multistage method of sampling was used to select a sample of 500 post menarche junior secondary school students. A structured questionnaire was used for data collection. Frequency tables were generated. Percentages and mean values with standard deviation were calculated. $70.9 \%$ of the respondents reported some challenges during their menstrual periods. Abdominal pains and cramps were the major challenges. $11.7 \%$ feel depressed. $63.9 \%$ do nothing to relieve the discomfort, while $17.5 \%$ visit a doctor for treatment. $83.4 \%$ use sanitary pads. About half of the respondents have challenges with getting good sanitary facilities and sanitary pads. $13.8 \%$ have absented themselves from school/examinations during menstruation as a result of severe menstrual pain [dysmenorrhoea].52.1\% of the students change their sanitary pads twice daily; and a majority of $83.9 \%$ bathe two or more times a day. Many of the students burn their sanitary material. A minority flush their sanitary pads in the toilets. Increase in public enlightment in the society and increase in the toilet facility in the schools were suggested as ways of improving menstrual hygiene practice.
\end{abstract}

Keywords: Menstrual hygiene, Menstruation, Menarche, Sanitary pads, menstrual cycle.

\section{Introduction}

Menstruation and menstrual hygiene are issues which every girl and woman will have to contend with in her life time. Coping with menstruation can be an enormous task. Menstruation is defined as the cyclical shedding of the inner lining of the uterus, the endometrium, under the control of hormones of the hypothalamo-pituitary axis. (Aniebue U., Aniebue P., Nwankwo 2009). The period between the first day of a menstrual period to the onset of the next menstrual period is called a menstrual cycle. An average menstrual cycle is twenty-eight days . Menstruation last for a period of three to five days. This is called a menstrual period. The first menstrual period, which a girl experiences, is called menarche. Menarche occurs between nine and fifteen years. Menarche signals reproductive maturity. Menarche often comes with anxiety, Fear, confusion and depression. (Marianne, Pherson and Korline 2004 as in Aniebue et al 2009) on the other hand, menarche is celebrated in some cultures and gifts are given to the young girl.

Keeping clean and tidy (hygiene) during menstrual period is a problem to many young girls, especially where information on menstruation and reproductive health are poorly discussed. Issues relating to the practical management of menstrual hygiene are very important because it has health implications in terms of vulnerability to infections. (Anuradha 2011) The absorbent materials used as well as their mode of usage contribute to the health status of the users. On menstrual hygiene practices, Johnson (2010) opined that "there are no 'correct' practices and many of these issues surrounding menstrual hygiene are dependent on finances and cultures. According to her, it 
is important to maintain a high standard of hygiene during menstruation as any bacteria on the hand before changing pads can be transferred into the vagina and cause infection and any bacteria from the vagina following changing of pads can be transferred to other items. Furthermore, she reported that a lot of women feel uncomfortable during menses and they wish to bath often. She is of the view that there is no need to wash inside the vagina during menses as washing disturbs the natural floral of the body and increase the risk of infection. On sexual intercourse during menses, Johnson (2010) advocates that if both parties agree, they can have it. There is a general consensus on changing sanitary towels regularly (as often as three to four times a day), as well as bathing (Bhomia 2010, Pouresiami, Mohammad, Osati-Ashtiani, Farzaneh 2002, Oyegbeda 2000, Anyakoha 2010).

Different cultures and religions view menses in different ways. Traditionally, in Africa, a menstruating woman is not expected to associate closely with her husband, his room, his food, and his shrine. This has psycho-social effect on the women. Also, the major world religions share the view that a menstruating woman should be secluded or excluded from certain places and activities. Banes and Philpps (1980), in Guterman, Mehta and Gibbs (2008) reported that there are some Christian denominations who exclude women from some activities, such as receiving communion during menses. Guterman et al (2008), quoting Whela (1975) writes "in Muslim religion, 'impure' (menstruating) women are to be avoided by men. They should be left alone until they are cleansed and have purified themselves". Hinduism also views the menstruating woman as impure and polluted. (Fischer, 1978. Whela, 1975 in Gutermal et al, 2008).

Menstruation is an important part of the physiology and life experience of women. It affects the reproductive health and productivity of women to a large extent. Menstrual hygiene is scantily taught under puberty in the schools. The issue is not given sufficient attention at the junior secondary school level. A lot of girls and women do not have sufficient knowledge about this issue. Facilities to promote healthy menstrual hygiene are lacking in many schools. The obvious implication here is that the individual of this age group may be faced with the risk of having short and long term health implications. The irony is that in spite of the importance of this subject matter, there is scarcity of information in literature and it has also not attracted serious attention by the citizenry. The study was embarked on to find out if junior secondary school students practice good menstrual hygiene and whether they face challenges during menstrual periods, with its implication for Home economics education.

\section{Methodology}

The researcher adopted the survey method of research, collected and analysed data from a representative sample of the population of post-menarche girls of junior secondary schools.

The population of the study was made up of the post-menarche girls in all the Junior Secondary Schools in Benin City. They need adequate information on menstrual hygiene. A representative sample of 500 post menarche junior secondary school students were used for the study. The multistage method of sampling was used. The schools in Oredo Local Government Area were zoned into five groups by location. Two schools were randomly selected from each zone. Fifty questionnaires were administered in each of the schools to get the representative sample of 500 students.

A structured questionnaire titled Menstrual Hygiene Practices (MHP) was used as instrument of data collection. The questionnaire was made up of two sections. Section A. contained three items for bio-data while section B. had eighteen (18) items where respondents were required to tick selected options.

The data were fed into a computer and analysed, using the Microsoft Excel electronic spread sheet, Office 2007 version. Frequency tables were generated. In addition, percentages and mean values with standard deviation were calculated. 


\section{Results}

Five hundred (500) questionnaires were distributed and collected. 494 were sufficiently filled for analysis. The mean age of the respondents was $14.3 \pm 1.3$, range 12 to 17 years. Figure 1 , shows the age in years, the age group 14-15 was the most common $(43.7 \%)$, next $12-13$ years $(34.2 \%)$. The average age at first menstruation was $12.88 \pm 1.1$ years, range 10-15 years. Figure2 shows that 65.8 percent of the respondents have their first menstruation (menarche) between 12 and 13 years of age, while 24.3 percent of the student experience menarche at 14-15 years. Christian's respondents were the majority $(92.3 \%)$, while traditional African religion made up $5.1 \%$. Table 1 is a summary of the respondents' religion. 451 (91.5\%) of the respondents had knowledge about menstruation before their menarche, while $42(8.5 \%)$ had no information. Mothers were the major source of information $238(52.2 \%)$, next is teacher $156(34.2 \%)$, and sisters $52(11.4 \%)$. Table 2 shows the respondents' information source about menses before menarche.

The majority of respondents $480(97.4 \%)$ think that menstruation is a normal body function, while $13(2.6 \%)$ think it is a disease condition. Majority of the respondents, $395(84.5 \%)$ could explain the function of the menstrual cycle. Figure 3 depict the responses of the students to the question can you explain what the menstrual cycle is about?

A total number of $349(70.9 \%)$ of the respondents reported some form of disturbance and or inconveniences during their menstrual periods. $143(29.1 \%)$ have none. Abdominal pains and cramps were the major complaints 264 (75.6\%), next is feeling depressed, $41(11.7 \%)$ of the respondents. Table 3 is a summary of the disturbance /inconveniences reported felt by the students. A large majority $63.9 \%$ do nothing to relieve the discomfort, while $61(17.5 \%)$ visit a doctor for treatment as shown in table 4. Table 5 shows the distribution of the sanitary materials used to collect menstrual blood by respondents in the study. Eighty three $(83.4 \%)$ use sanitary pads, while none $(0.0 \%)$ use the Tampons. Sixty eight $68(13.8 \%)$ students have absented themselves from school during menstruation (Table 6). The major reason from absenteeism from school/examinations was severe menstrual pain [dysmenorrhoea] 49 (72.1\%) students (Table7), while no student absented because of religious ground. More than half $(52.1 \%)$ of the student change their sanitary pads twice daily (Table 8); and a majority of $83.9 \%$ (Table 9) bathe two or more times a day. Most of the students burn their sanitary material $(39.6 \%)$ as shown in table 10 , but a small minority (16.5\%) flush their sanitary pads in the toilets.

A large majority, $93.9 \%$ of the students felt that enough of information is being taught on menstrual hygiene in the school curriculum (table 11). To improve awareness of menstrual hygiene practice among teenage girls, a large majority $(47.3 \%)$ advocated for an increase in public enlightment and discussion to be organised in the society, $15.8 \%$ suggested an increase in the toilet facility by government in the public schools. Table 12 shows the different suggestions made by the students to improve menstrual hygiene practices.

\section{Discussion}

It is evident from the result of the study that most of the students have some information about menstrual hygiene before their first menstrual period. This agrees with the result of study conducted by Wateraid in Nepal. ( Wateraid, 2009) The major source of the information to the students is their mothers, closely followed by their teachers. This shows that adequate knowledge about menstrual hygiene is imparted to the students during school work. This is further confirmed by the result of the study where many of the students saw no need to teach menstrual hygiene more extensively in schools. Most of the students are aware that menstruation is a normal body function and can explain what the menstrual cycle is about. Majority of the students use disposable sanitary pads as absorbent materials to collect their menstrual blood. This is unlike Wateraid's study of adolescent school girls where more of them make use of new pieces of cloth.(Wateraid, 2009) More than half of the students change their sanitary towels, and take their bath two or more 
times daily. Majority of the students dispose of their used absorbent materials by burning or putting them in refuse dumps. The study show that they are not secluded or excluded by any cultural or religious taboo as reported by Banes et al in1980 in Guterman et al (2008). Many of the students experience abdominal pains during their menstrual period, but do nothing to relieve it while few of them visit a doctor. A few of them absent themselves from school as a result of abdominal pains. A few of them also feel depressed during their menstrual period. A large majority of the students advocate for an increase in public enlightenment and discussion to be organised in the society as a measure to increase awareness about menstrual hygiene.

\section{Conclusion}

The standard of menstrual hygiene practice amongst Junior Secondary school girls in Benin City is lofty (high). There is need to increase and sustain the present level of awareness as a significant minority flush their sanitary pads in the toilet. . The objective of helping students to develop good menstrual hygiene practices, in teaching menstrual hygiene, as a sub-topic under puberty, in JSS 2 Home economics is achieved among Junior Secondary School students in Benin City

\section{Recommendations}

From the study, it is recommended that the government should improve and increase toilet and other sanitary facilities in the schools. home.

House owners, parents and guardians should improve toilet and other sanitary facilities at

Parents and guardians should provide adequate sanitary towels for their children during menstrual periods.

Figure 1: Age in years

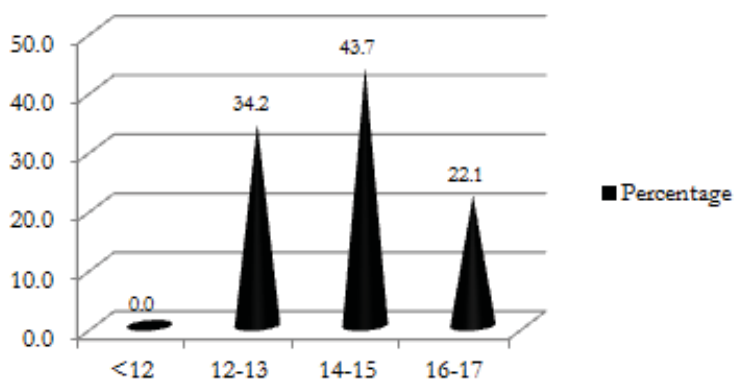

Figure 2: Age at Menarche

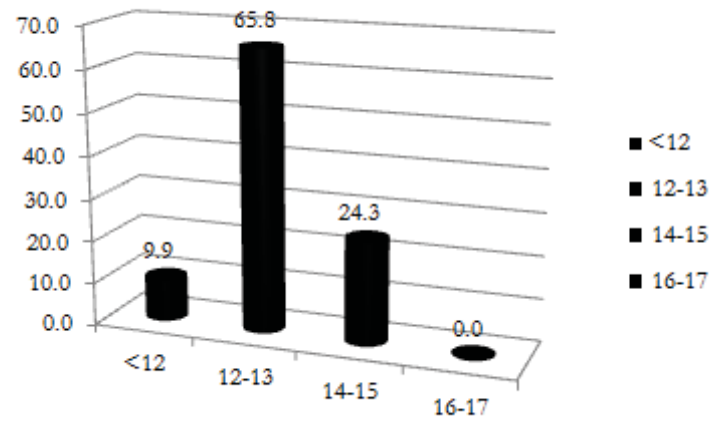


Table 1. Respondents' religion

\begin{tabular}{lcc}
\hline \multicolumn{1}{c}{ Religion } & No & Percentage \\
\hline Christianity & 456 & 92.3 \\
Traditional African religion & 25 & 5.1 \\
Islam & 13 & 2.6 \\
Judaism & 0 & 0.0 \\
Hindu & 0 & 0.0 \\
Total & 494 & 100.0 \\
\hline
\end{tabular}

Table 2. Source of Information

\begin{tabular}{lcc}
\hline \multicolumn{1}{c}{ Sources } & No & Percentage \\
\hline Mother & 238 & 52.2 \\
Teacher & 156 & 34.2 \\
Sister & 52 & 11.4 \\
TV/Electronic Media & 10 & 2.2 \\
Other Relative & 0 & 0.0 \\
Total & 456 & 100.0 \\
\hline
\end{tabular}

Table 3: Disturbances experienced during menses

\begin{tabular}{lcc}
\hline \multicolumn{1}{c}{ Disturbance } & No & Percentage \\
\hline Abdominal Pains and Cramps & 264 & 75.6 \\
Depression & 41 & 11.7 \\
Feeling Sick & 22 & 6.3 \\
Weakness \& unable to walk & 13 & 3.7 \\
Vomiting & 9 & 2.6 \\
Poor concentration & 0 & 0.0 \\
Total & 349 & 100.0 \\
\hline
\end{tabular}

Figure 3: Explain Menses

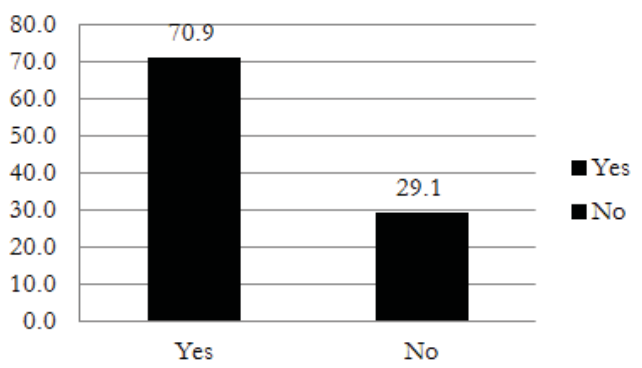

Table 4: Remedy sort for disturbance relief

\begin{tabular}{lcc}
\hline \multicolumn{1}{c}{ Relief } & No & Percentage \\
\hline Nothing & 223 & 63.9 \\
Visit a Doctor & 61 & 17.5 \\
Buy medicine form chemist & 46 & 13.2 \\
Given drugs by parents & 19 & 5.4 \\
Total & 349 & 100.0 \\
\hline
\end{tabular}


Table 5. Absorbent material used by respondents

\begin{tabular}{lcc}
\hline \multicolumn{1}{c}{ Absorbent } & No & Percentage \\
\hline Sanitary pad & 412 & 83.4 \\
Pieces of clothe & 34 & 6.9 \\
Toilet Tissue paper & 27 & 5.5 \\
Menstrual cup & 14 & 2.8 \\
Reusable sanitary materials & 7 & 1.4 \\
Tampons & 0 & 0.0 \\
Total & 494 & 100.0 \\
\hline
\end{tabular}

Table 6. Number of respondents absent from school

\begin{tabular}{ccc}
\hline Absent & No & Percentage \\
\hline Yes & 68 & 13.8 \\
No & 423 & 86.2 \\
Total & 491 & 100.0 \\
\hline
\end{tabular}

Table 7. Reasons for being absent from school

\begin{tabular}{lcc}
\hline \multicolumn{1}{c}{ Reason } & No & Percentage \\
\hline Severe pains (Dysmenorrhea) & 49 & 72.1 \\
Nothing & 11 & 16.2 \\
Inadequate toilet facility at school to change & 8 & 11.8 \\
My Religion forbids me doing anything & 0 & 0.0 \\
Total & 68 & 100.0 \\
\hline
\end{tabular}

Table 8. How often do you change your absorbent (Sanitary) material

\begin{tabular}{lcc}
\hline \multicolumn{1}{c}{ Change } & No & Percentage \\
\hline Once daily & 38 & 7.8 \\
Twice Daily & 253 & 52.1 \\
Three or more times daily & 181 & 37.2 \\
At the end of my menses & 14 & 2.9 \\
Total & 486 & 100.0 \\
\hline
\end{tabular}

Table 9. How often do you bathe during your menstrual periods

\begin{tabular}{lcc}
\hline \multicolumn{1}{c}{ Bathe } & No & Percentage \\
\hline Never & 7 & 1.5 \\
Once a day & 54 & 11.3 \\
Two or more times daily & 398 & 83.3 \\
At the end of my menses & 19 & 4.0 \\
Total & 478 & 100.0 \\
\hline
\end{tabular}

Table10. Method of disposal of used sanitary material

\begin{tabular}{lcc}
\hline \multicolumn{1}{c}{ Disposal Method } & No & Percentage \\
\hline By burning & 182 & 39.6 \\
Put away in a refuse dump & 96 & 20.9 \\
In a pit latrines & 106 & 23.0 \\
Flushing in the toilet & 76 & 16.5 \\
Total & 460 & 100.0 \\
\hline
\end{tabular}


Table 11. Do you think enough is thought in school

\begin{tabular}{ccc}
\hline Information & No & Percentage \\
\hline Yes & 462 & 93.9 \\
No & 30 & 6.1 \\
Total & 492 & 100.0 \\
\hline
\end{tabular}

Table 12. Suggestions to improve awareness among teenage girls

\begin{tabular}{lcc}
\hline \multicolumn{1}{c}{ Suggestion } & No & Percentage \\
\hline Include subject in family & 153 & 31.9 \\
life education curriculum & 227 & 47.3 \\
Public enlightment and discussion & 24 & 5.0 \\
Remove taboos about discussion & 0 & 0.0 \\
Religious bodies to encourage discussion & 76 & 15.8 \\
Government to provide adequate toilet / & 480 & 100.0 \\
Sanitary facilities in schools & \\
Total
\end{tabular}

\section{References}

Aniebue U. U., Aniebue P. N.,Nwankwo Theophilus Ogochukwu. (2009). The Impact of Pre- menarche Training on Menstrual Practices and Hygiene of Nigerian School Girls The Pan African Medical Journal, June 2009. Retrieved on 15/08/2011 from http://www.ncbi.nlm.n.h.gov/pmc/articles /pmc2984277.

Anuradha Kerala (2011). Menstrual Hygiene Practices and Reproductive Morbidity. A Community Based Survey in Rural Thruvananthapuram. Retrieved on 15/08/2011 from http://www.sctimst.ac.in /amchss/research/ge3.htm.

Anyakoha Elizebeth U, (2010). Home Economics for J unior Secondary Schools. . Onitsha,Nigeria. Africana First Publishers Limited.

Bhomia A. (2010) Unhygienic Menstrual Conditions Taking Life While We Do Nothing About It. Retrieved on 15/08/2011 from http://www.youthkiawaaz.com/2010/10 .

Guterman M.A., Mehta P.,Gibbs M.S. (2008). Menstrual Taboos Among Major Religions. The Internet J ournal of World Health and Societal Politics. Vol. 5 No. 2. Retrieved from http://www.ispub.com /J ournal .on 16/8/2011.

J ohnson Jo. (2010) Menstrual Hygiene. Retrieved on 8/8/2011 from http://www. hygiene.html.

Oyegbeda Rebecca, (2009). Modern Home Economics for J.S.S. 1, 2 and 3. Benin city. Antie Becky Publishing Company

Pouresiami Mohammad, Osati Ashtiani, Farzaneh, (2002) Assessing, Knowledge, Attitude and Behaviour of Adolescent Girls in Suburban Districts of Tehran about Dysmenorrhea and Menstrual Hygiene. Journal of International women Studies. Retrieved 8/8/2011 from http://www.thefreelibrary.com /assessing+knowlrdge+attitudes+and+behaviourofad .

Wateraid (2009). Is Menstrual Hygiene and Management an Issue for Adolescent School Girls? A Comparative Study of Four Schools in Different Settings of Nepal. Retrieved 8/8/2011. http://www.wateraid.org/documents/plugin_documents/wa_nep_mhm_nepa_march2009 
